Volume 2 Issue 2

December 2017

\title{
What Australian and Irish paramedic registrants can learn from the UK: lessons in developing professionalism.
}

Ruth Townsend BN LLB LLM DipParaSc GradDipLegalPrac GradCertVET Associate Editor, Irish Journal of Paramedicine

Charles Sturt University, NSW, Australia

\section{Recommended Citation}

Townsend, R. What Australian and Irish paramedic registrants can learn from the UK: lessons in developing professionalism. Irish Journal of Paramedicine. 2017 Dec; 2(2).

\footnotetext{
This is an Open Access article distributed under the terms of the Creative Commons Attribution-Non-Commercial-ShareAlike 4.0 International (http://creativecommons.org/licenses/by-nc-sa/4.0/), which permits use, distribution, and reproduction in any medium, provided the original work and any attributes thereof are properly cited, are distributed under the same licence, and that the work is not used for commercial purposes.
}

Follow the Irish Journal of Paramedicine online at www.irishparamedicine.com, on Twitter (@irishjparamed) and on Facebook. 
EDITORIAL

\title{
What Australian and Irish paramedic registrants can learn from the UK: lessons in developing professionalism.
}

\author{
Ruth Townsend BN LLB LLM DipParaSc GradDipLegalPrac GradCertVET ${ }^{1,2}$
}

\section{Charles Sturt University, NSW, Australia.}

Correspondence: Ruth Townsend, Charles Sturt University, NSW, Australia. Email: rtownsend@csu.edu.au

\section{Key points}

- To act with professionalism is to act within a set of moral norms, principles and standards of conduct and competency

- $\quad$ Problems arise when paramedics do not understand what it means to be a professional, and this is largely due to gaps in education.

- $\quad$ Regulation should not be seen as a threat, but rather as a positive way of advancing the profession, and focussing on doing the best for patients.

- $\quad$ Education plays a key role in creating a culture of professionalism, a solid foundation of professionalism and a professional identity. This education must be consistent.

- $\quad$ Paramedics should be supported in their professional development with a greater emphasis on applied ethics to facilitate professional problem-solving and a more comprehensive understanding of the regulatory system.

As Australian paramedics begin a transition to registration under a national regulatory framework, they can look to the experience of paramedics in the United Kingdom to help identify areas of difficulty early on, and work to prevent significant problems before they arise.

In September 2017, legislation was passed in Australia that will allow paramedics to be regulated as professionals for the first time.(1) Australian paramedics have been pursuing a professionalisation project for approximately a decade (2-5) and regulation under the Health Practitioner Regulation National Law Act (1) ('National Law') will help them achieve a number of their objectives, including, that they will be able to unify, organise and self-regulate as one unique discipline under their own Paramedicine Board.

The Paramedicine Board will have the power to develop, and be instrumental in establishing, a culture and ethos of professionalism for the new profession. Eliot Freidson, an American sociologist who spent three-decades thinking and writing about a theory of the professions said, 'the ideology of professionalism asserts, above all else, devotion to the use of disciplined knowledge and skill for the public good.' (6). The 'public good' includes acting altruistically, that is, putting the patient's interest before selfinterest. This principle of professionalism is codified in law in both the UK regulation and the Australian regulation.

Characteristics associated with healthcare professionalism are also recognised as including 'clinical excellence, altruism, pursuit of patients' best interests, patient advocacy, technical knowledge, professional responsibility, and self-governance'.(7) To act with professionalism is to act within a set of moral norms, principles and standards of conduct and competency. (8) Specifically with regard to healthcare professionals, it has been defined as 'a set of values, behaviours and relationships that underpins the trust [of] the public'.(9) Consistent with these principles are other examples of professionalism codified in the Australian law, arguably the most important and most generalised of which is that registered paramedics 'must not engage in conduct that is significantly below the standard reasonably expected of a practitioner of an equivalent level of training or experience.'(1)

The Paramedicine Board of Australia will have the power under the law to develop national 'training' and 'conduct' standards via provisions within the law that allow the Board to determine education, accreditation, registration, conduct, and competency standards, which will apply to the whole profession for the first time. (1) It is therefore incumbent upon the Board to ensure that the minimum standard of education they set to meet the requirements for registration as a paramedic in Australia are sufficient to ensure that the discipline's specialised knowledge and skill is able to be used for the 'public good.' (3). The importance of establishing clear and consistent education standards in order to develop a culture and ethos of professionalism is supported by a recent study into the complaints made against paramedics in the UK.

In 2016 the UK regulator, the Health and Care Professions Council (HCPC), commissioned a report by researchers at the University of Surrey to examine why UK paramedics and social workers were receiving high numbers of complaints. (10) The final report of the study, titled, 'People like us?' was made to the HCPC in late 2017. (11) The report noted a number of key issues that were contributing to the high complaint numbers, including that there were a large number of self-referral cases involving paramedics reporting other paramedics, suggesting that there was some misunderstanding of the self-reporting regulatory requirements. However, a number of other issues were also identified including that the challenging nature of the highly pressurised environment in which paramedics work, along with the evolving nature of the profession, and false public and societal expectations of the role of paramedics, have all contributed to complaints. These findings are relevant for 
Australian and Irish paramedics because the complex nature of paramedic work is universal, and the paramedic discipline is also evolving in Australia and Ireland.

There were further findings that may also be of some interest and relevance to the development of professionalism in Australian and Irish paramedicine. For example, the study recognised that the issue of professionalisation of paramedicine and the changing of roles and professional identity from being technicians following strict protocols, to professionals using discretionary decision-making, problem solving and the need to "provide solutions, is creating a more complex practice for paramedics." (12)

This increase in complexity of knowledge, skills and work comes with increased responsibility and accountability that requires a commensurate increase in education and professional development support. The study identified that issues with the delivery of the latter two elements could be factoring into the high numbers of complaints about paramedics and could be improved both by the College of Paramedics and with employers.(11) For example, there was some concern expressed by participants in the study regarding paramedic professionalism education including that it was "felt that for some paramedics there was a lack of understanding about what being a healthcare professional means and the 'ethical side' involved." (11)

Some suggestions were made by participants in the study as to how the College could improve this, including "guiding the profession to a greater appreciation of the meaning of professionalism and performance ethics" via the integration of ethical case studies into education and training. The key issue identified in the study across participants was the critical role of education in "laying the foundations for paramedics in understanding their professional role, their registration and regulations, and how to deal with challenges in practice." (11) There was also a suggestion that both paramedics and ambulance services/employers should be more aware of and alert to the HCPC's 'Standards of Conduct, Performance and Ethics' and that there needed to be more consistent delivery of modules regarding the role of the $\mathrm{HCPC}$, the guidelines, codes, policies and regulation that governs paramedics. This would facilitate the practice of paramedic professionalism and it would also provide assistance to employees who wished to raise concerns about performance matters that could potentially arise as a result of conflicts of interest between employer guidelines and professional standards. (13)

Another important issue identified in the study that is relevant for Australian paramedics (and less so, Irish paramedics, given their experience with a regulatory body for some time), is the need for the profession's leadership to raise awareness amongst members of the role of the regulator and purpose of the regulation to place the interests of the public first. Although this regulatory structure may appear as a 'threat' to paramedics because the regulator has, in effect, the power to remove the paramedic's 'licence to practice,' a more positive approach to understanding the objective of the regulator could be for paramedics to know that although they will be held to account under the regulation this can provide an opportunity for paramedics to focus their attention on matters of professionalism in their practice. One participant in the report said, "we have a responsibility as educators to ensure that students understand that it's actually it's not personal, it's about public safety and this is our registered professional body." (11) Of course this may only be possible if paramedics are supported by adequate professionalism education. Another participant noted that paramedic education needed to extend beyond just clinical skills to ensure that students have an understanding of and commitment to the development of their 'professional and personal conduct' so that it meets 'the standards that will be expected of you by the public and your regulator'. (11)

An interesting finding of the report that highlights cultural issues that may have developed as a result of a twotiered education pathway (i.e. university and vocational training) particular to paramedicine was the suggestion that those trained in a university were more likely to understand notions of professionalism than those who were not. These differences were related to the cultural approach to work that related to the historical command-and-control, protocoldriven (para-military) style as compared to the development of a more autonomous, independent, professional practitioner style encouraged by tertiary-level learning. The adoption of clear consistent education standards was suggested as a way to redress this cultural difference and raise awareness of the responsibilities and accountabilities associated with the professional behaviour expected of paramedics today and in that way help to facilitate a change in culture and practice. (11)

In short, the UK 'People like us?' report identified a number of relevant issues for the development of a culture and ethos of professionalism in paramedicine in the UK, Australia and Ireland. The key theme of the report was the importance of education and educators in providing a firm foundation of professionalism. (11). It identified that paramedics work in challenging practice environments and situation of 'extremis' with 'heightened situations of emotional and physical distress' and in uncontrolled environments like 'the side of a road, tight spaces in homes, off a cliff or on beach' that require them to rely on and use a range of high level clinical and non-clinical skills that are distinctly different from other healthcare practitioners.(11) This 'front line' response to crisis is associated with heightened emotions that 'can result in misperceptions and miscommunication' that may lead to complaints.(11) Additionally the study found that there were educational inconsistencies within the paramedic curricula and there was a lack of support for paramedic professional development amongst employers. The lack of educational support extended to include not only communication skills but also issues with 'the quality of ethics education [in that it] is not strong 
enough.' (11)

This suggests that an approach to addressing some of these issues is to improve the way communication skills are taught and developed in paramedics. The unique nature of the environment in which paramedics work serves to highlight the importance of the development of high level communication skills and this is something that should be more heavily focused on in paramedic curricula. Likewise, the report found that the complex nature of the work paramedics do means that they require high level critical thinking and ethical training in order to ensure that they act with professionalism and are capable of delivering high quality, safe care to patients that is consistent with Freidson's ideology of professionalism as 'devotion to the use of disciplined knowledge and skill for the public good.' (3).

Australia now joins the small, yet ever-increasing pool of countries with national regulation for paramedicine. It remains to be seen exactly how the leaders of the new profession will approach the unification of the discipline and establish a culture and ethos of professionalism beyond that prescribed by the National Law; however, I am optimistic that lessons learned from the UK and elsewhere will help inform the Board of a number of mechanisms that it has available to it to do so.

\section{References}

1. Health Practitioner Regulation National Law Act 2009 (Q1d) Schedule 1. The law is an example of cooperative federalism and has been copied or adopted with amendments by all other states and territories see: Health Practitioner Regulation National Law 2010 (ACT); Health Practitioner Regulation National Law 2009 (NSW); Health Practitioner Regulation National Law (National Uniform Legislation) Act 2009 (NT); Health Practitioner Regulation National Law (South Australia) Act 2010 (SA) Schedule 2; Health Practitioner Regulation National Law (Tasmania) 2010 (Tas); Health Practitioner Regulation National Law 2009 (Vic); Health Practitioner Regulation National Law 2010 (WA).

2. Reynolds, L. Is prehospital care really a profession? Australasian Journal of Paramedicine, 2004; 2(1).

3. Grantham, H. Prehospital Care as a Profession-Are we there yet? Australasian Journal of Paramedicine, 2004; 2(1).

4. FitzGerald, G., \& Bange, R. Defining a regulatory framework for paramedics: a discussion paper. Australasian Journal of Paramedicine, 2007; 5(2).

5. O'Meara, P. Paramedics marching towards professionalism. Journal of Emergency Primary Health Care, 2009; 7(1), 1-3.

6. Freidson, E. Professionalism, the third logic: On the practice of knowledge. 2001; University of Chicago press.

7. Vicarelli, G., \& Spina, E. Professionalization and Professionalism: the Case of Italian Dentistry. Professions and Professionalism, 2015; 5(3).

8. Evetts, J. The concept of professionalism: Professional work, professional practice and learning. In International handbook of research in professional and practice-based learning (pp. 29-56). 2014; Springer Netherlands.

9. Tallis, R. C. Doctors in society: medical professionalism in a changing world. Clinical Medicine, 2006; 6(1), 7-12.

10. Health and Care Professions Council. Fitness to Practice Annual Report 2016, viewed https:/www.hcpcuk.org/assets/ documents/100051F3Fitnesstopracticeannualreport2016.pdf 11. van der Gaag, A et al. 'People like us? Understanding complaints about paramedics and social workers.' Final Report. 31 August 2017. Viewed http://www.hcpc-uk.org/ assets/documents/1000558EPeoplelikeusFinalReport.pdf

12. O'Meara et al (2009). cited in van der Gaag, A et al. 'People like us? Understanding complaints about paramedics and social workers.' Final Report. 31 August 2017. http:// www.hcpc-uk.org/assets/ documents/1000558EPeoplelikeusFinalReport.pdf 13. Baron, A., \& Townsend, R. Live tweeting by ambulance services: a growing concern. Journal of Paramedic Practice, 2017; 9(7), 282-286.

Author contributions: RT was author of the manuscript, and performed the final editing.

Source of support/funding: None.

Conflict of interest: RT is Associate Editor of the IJP.

Provenance and review: Commissioned, not peerreviewed.

This is an Open Access article distributed under the terms of the Creative Commons Attribution-Non-Commercial-ShareAlike 4.0 International (http:// creativecommons.org/licenses/by-nc-sa/4.0/), which permits use, distribution, and reproduction in any medium, provided the original work and any attributes thereof are properly cited, are distributed under the same licence, and that the work is not used for commercial purposes. Content copyright remains with the authors, who grant the IJP a licence to reuse and distribute. 